Article

\title{
Oxygen Adsorption and Activation on Cobalt Center in Modified Keggin Anion-DFT Calculations
}

\author{
Renata Tokarz-Sobieraj ${ }^{1, *(D)}$ and Piotr Niemiec ${ }^{2}$ (D) \\ 1 Jerzy Haber Institute of Catalysis and Surface Chemistry, Polish Academy of Sciences, Niezapominajek 8, \\ 30239 Krakow, Poland \\ 2 Faculty of Mathematical and Natural Sciences, Department of Chemistry, University of Applied Sciences in \\ Tarnow, Mickiewicza 8, 33100 Tarnow, Poland; p_niemiec@pwsztar.edu.pl \\ * Correspondence: nctokarz@cyf-kr.edu.pl; Tel.: +48-12-6395152
}

Received: 11 December 2019; Accepted: 14 January 2020; Published: 21 January 2020

\begin{abstract}
The influence of the cobalt cation geometric environment on catalytic activity, namely, oxygen adsorption and its activation, was investigated by exploring two groups of systems. The first group was formed by cobalt cation complexes, in which the $\mathrm{Co}^{2+}$ was surrounded by water- $\mathrm{H}_{2} \mathrm{O}$ or acetonitrile- $\mathrm{CH}_{3} \mathrm{CN}$ solvent molecules. This represents heteropolyacids salts $\left(\mathrm{Co}_{\mathrm{n}} \mathrm{H}_{3-\mathrm{n}} \mathrm{PW}(\mathrm{Mo})_{12} \mathrm{O}_{40}\right)$, where the $\mathrm{Co}^{2+}$ acts as a cation that compensates for the negative charge of the Keggin anion and is typically surrounded by solvent molecules in that system. The second group consisted of tungsten or molybdenum Keggin anions $\left(\mathrm{H}_{5} \mathrm{PW}_{11} \mathrm{CoO}_{39}\right.$ and $\left.\mathrm{H}_{5} \mathrm{PMo}_{11} \mathrm{CoO}_{39}\right)$, having the $\mathrm{Co}^{2+}$ cation incorporated into the anion framework, in the position of one addenda atom. Detailed NOCV (Natural Orbitals for Chemical Valence) analysis showed that, for all studied systems, the $\sigma$-donation and $\sigma$-backdonation active channels of the electron transfer were responsible for the creation of a single $\mathrm{Co}-\mathrm{OO}$ bond. Depending on the chemical/geometrical environment of the $\mathrm{Co}^{2+}$ cation, the different quantities of electrons were flown from the $\mathrm{Co}^{2+} 3 d$ orbital to the $\pi^{*}$ antibonding molecular orbitals of the oxygen ligand, as well as in the opposite direction. In molybdenum and tungsten heteropolyacids, modified by $\mathrm{Co}^{2+}$ in the position of the addenda atom, activation of $\mathrm{O}_{2}$ was supported by a $\pi$-polarization process. Calculated data show that the oxygen molecule activation changed in the following order: $\mathrm{H}_{5} \mathrm{PMo}_{11} \mathrm{CoO}_{39}=\mathrm{H}_{5} \mathrm{PW}_{11} \mathrm{CoO}_{39}>\mathrm{Co}\left(\mathrm{CH}_{3} \mathrm{CN}\right)_{5}{ }^{2+}>\mathrm{Co}\left(\mathrm{H}_{2} \mathrm{O}\right)_{5}{ }^{2+}$.
\end{abstract}

Keywords: cobalt-modified heteropoly compounds; molecular oxygen activation; DFT (Density Functional Theory) calculations; NOCV analysis

\section{Introduction}

The acid-base and redox properties of heteropoly compounds (POM-PolyOxoMetalate) are particularly attractive from a catalytic and research point of view [1-3]. In recent years, in addition to commonly used 12-tungsto and 12-molybdo-phosphoric acids and their salts, systems modified by transition metal cations have been used [4-6]. The transition metal cation may be introduced into the heteropoly compounds in a position of compensating/counter cation, central ion/heteroatom or addenda atom(s). Depending on its location in the geometric structure, new elements may discern acidic and/or oxidizing properties.

One of the elements commonly used in POM modification is cobalt, and the catalysts obtained in this way are successfully used in many different catalytic reactions [7-45]. Keggin-type catalysts, with a cobalt cation $\left(\mathrm{Co}^{2+}\right)$ in the position of the central ion, were tested in catalytic reactions, primarily as an acid $\left(\mathrm{H}_{6} \mathrm{CoW}_{12} \mathrm{O}_{40}\right)$ [7,8] or as salts, e.g., potassium $\left(\mathrm{K}_{5} \mathrm{CoW}_{12} \mathrm{O}_{40}{ }^{*} 3 \mathrm{H}_{2} \mathrm{O}\right)$ [9-12]. The acid properties of the systems were tested in reactions, such as: MTBE (Methyl tert-butyl ether) synthesis [7], decomposition of isobutyl propionate (IBP) [8], acetylation of alcohols and phenols [9], deprotonation 
of THP (Tetrahydropyranyl) esters [10], alcoholysis and acetolysis of epoxides, and conversion of epoxides to thiiranes [11], and formation of 1, 3-dioxolanes from epoxides [12]. Since the change in the central ion position results in the change in the oxidizing potential of the heteropoly anion [1,13-15], $\mathrm{CoW}_{12} \mathrm{O}_{40}{ }^{6-}$ systems were successfully used in the oxidation of benzol alcohol [16].

A review of the literature shows greater attention given to systems where the cobalt cation $\left(\mathrm{Co}^{2+}\right)$ occupies the position of the addenda atom [17-39]. Modified systems, usually synthesized as various salts, as well as the comparison with systems modified by other transition metals, were tested in oxidation reactions in the presence of hydrogen peroxide [17-22], molecular oxygen [23-28], air [29-33], iodosylarenes [35,36], or t-butyl hydroperoxide [37,38]. Cobalt-modified Keggin heteropolyanin exhibits high catalytic activity and selectivity in processes such as oxidation of cyclohexane [26,27,35,37,38,40], esterification of n-butanol [25,39], epoxidation of olefins (cyclohexane, 1-hexene, norbornene, cyclooctene) [25], phenol oxidation [23], oxidation of methyl isobutyrate [24], oxidation of alpha-pinene [40], oxidation of alcohols 2-propanol [19] and hexanol [20], and lactonization of diols [22].

Cobalt heteropolyacids salts, where $\mathrm{Co}^{2+}$ occupies the position of the counter cation in the secondary structure of heteropoly compounds, were tested in the oxidation reaction. As shown by experimental data, the electronegativity of the counter-cations is very important in determining the reduction potentials of HPAs (Heteropolyacids). Pamin et al. [41] examined the aerobic oxidation of cyclooctane of free and chitosan-supported cobalt 12-tungstophosphates and 12-molybdophosphates, showing that the introduction of $\mathrm{Co}^{2+}$ cations into the $\mathrm{PW}_{12} \mathrm{O}_{40}{ }^{3-}$ HPA causes a significant increase in its oxidizing power, whereas the same cation introduced into the $\mathrm{PMo}_{12} \mathrm{O}_{40}{ }^{3-}$ system minimally increases its oxidizing abilities. Karcz et al. [42] compared heteropolyacid systems, modified by a cobalt cation in the position of the central ion and addenda atom, which showed that both cobalt locations and the chemical character of other addenda atoms factor into the catalytic activity of the aerobic liquid-phase oxidation of cyclooctane.

In recent years, the ability of heteropoly systems, modified by transition metal, to form complexes with $\mathrm{CO}_{2}$ has been studied. As shown by Chen et al. [43] and Yasada et al. [44], the highest catalytic activity was derived from systems modified by the $\mathrm{Co}^{2+}$ cation. In addition, the Szczepankiewicz [45] studied systems, where $\mathrm{Co}^{2+}$ was located in various heteropoly anions, namely the alfa-Keggin $\left(\mathrm{XW}_{11} \mathrm{O}_{39} \mathrm{TM}\right)$, alfa1/alfa2-Dawson $\left(\mathrm{P}_{2} \mathrm{~W}_{17} \mathrm{O}_{61} \mathrm{TM}\right)$, and Weakley and Finkey $\left(\mathrm{P}_{2} \mathrm{~W}_{18} \mathrm{O}_{68} \mathrm{Co}_{4}\right)$ showed that the ability to bind the $\mathrm{CO}_{2}$ molecule strongly depended on the geometric environment of the cobalt cation.

The theoretical calculations concerning this topic are rather poor [46-48]. Zhang and Maestre [46,47] studied the thermal stability and redox properties of the $\mathrm{CoW}_{12} \mathrm{O}_{40}{ }^{5-}$ alpha/beta Keggin anion. In Reference [48], the scope of the research was extended to $\mathrm{Co}^{3+}$ systems, in which the cobalt cation replaces the central ion and one of the addenda atoms in tungsten Keggin anions. For the studied systems, several lower-lying electronic states, as well as a vibrational analysis, were calculated. In our previous calculations [42], the effect of cobalt location in Keggin-type heteropoly acts as a catalyst for the aerobic oxidation of cyclooctane.

The aforementioned examples indicate that the location of the transition metal cation in the structure of the heteropoly systems had a significant bearing on the resulting catalytic properties. Therefore, the present paper describes our findings concerning the role of geometric structure on the catalytic properties of $\mathrm{Co}^{2+}$ cation, in the process of oxygen adsorption and its activation on the metal center. Using theoretical methods, both processes were tested using two groups of cobalt modified systems. The first group was formed by cobalt cation complexes, where the $\mathrm{Co}^{2+}$ cation is surrounded by water $\left(\mathrm{H}_{2} \mathrm{O}\right)$ or acetonitrile $\left(\mathrm{CH}_{3} \mathrm{CN}\right)$ solvent molecules. This represents heteropolyacids salts $\left(\mathrm{Co}_{n} \mathrm{H}_{3}-\mathrm{nPW}(\mathrm{Mo})_{12} \mathrm{O}_{40}\right)$, where the $\mathrm{Co}^{2+}$ acts as a cation that compensates for the negative charge of the Keggin anion, and which is typically surrounded by solvent molecules. The second group consisted of tungsten or molybdenum Keggin anions $\left(\mathrm{H}_{5} \mathrm{PW}_{11} \mathrm{CoO}_{39}\right.$ and $\left.\mathrm{H}_{5} \mathrm{PMo}_{11} \mathrm{CoO}_{39}\right)$, having the $\mathrm{Co}^{2+}$ cation incorporated in the position of one addenda atom. The purpose of the presented calculations 
is to explain the mechanism of the interaction of cobalt-oxygen complexes in the vicinity of various ligands. The calculations do not take into account the stability of complexes with various ligands and the energy of the ligand exchange process. These issues will be the subject of a separate publication (in preparation), where cobalt complexes will be compared with other transition metal complexes. From the literature and our unpublished calculations, it follows that some ligands, especially those containing nitrogen moieties, favor the exchange with the $\mathrm{O}_{2}$ molecule $[49,50]$. Our unpublished calculations of HPA complexes show that, e.g., water and acetonitrile are not exchanged with the $\mathrm{O}_{2}$ molecule, but are exchanged with $\mathrm{OOH}$ or $\mathrm{H}_{2} \mathrm{O}_{2}$.

\section{Results and Discussion}

The optimized geometries, obtained as a result of the interaction between the oxygen molecule and the studied systems, are shown in Figure 1. Table 1 presents the theoretical parameters describing the metal-oxygen (Co-O) and oxygen-oxygen $(\mathrm{O}-\mathrm{O})$ bonds, namely the bond distance, $d[\AA]$, and Mayer bond order indexes, $\mathrm{BO}[51,52]$. In addition, in the first row, the binding energy, $\Delta \mathrm{E}_{\mathrm{B}}[\mathrm{kJ} / \mathrm{mol}]$, which was calculated for the processes (1-3) presented below is summarized.

$$
\begin{aligned}
\mathrm{Co}\left(\mathrm{H}_{2} \mathrm{O}\right)_{5}{ }^{2+}+\mathrm{O}_{2} & =\text { OO- } \mathrm{Co}\left(\mathrm{H}_{2} \mathrm{O}\right)_{5}{ }^{2+} \\
\mathrm{Co}\left(\mathrm{CH}_{3} \mathrm{CN}\right)_{5}{ }^{2+}+\mathrm{O}_{2} & =\mathrm{OO}-\mathrm{Co}\left(\mathrm{CH}_{3} \mathrm{CN}\right)_{5}{ }^{2+} \\
\mathrm{HPW}(\mathrm{Mo})_{11} \mathrm{Co}+\mathrm{O}_{2} & =\mathrm{HPW}(\mathrm{Mo})_{11} \mathrm{Co}-\mathrm{OO}
\end{aligned}
$$

(a)

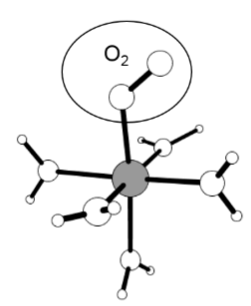

$\mathrm{OO}-\mathrm{Co}\left(\mathrm{H}_{2} \mathrm{O}\right)_{5}^{2+}$ (b)

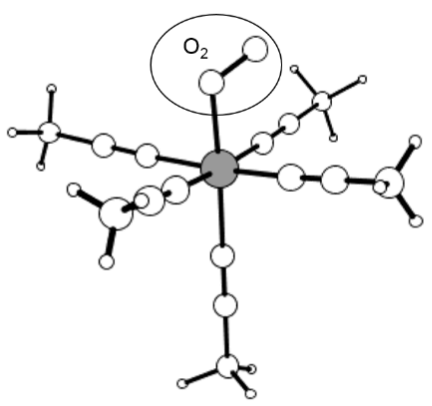

$\mathrm{OO}-\mathrm{Co}\left(\mathrm{CH}_{3} \mathrm{CN}\right)_{5}^{2+}$ (c)

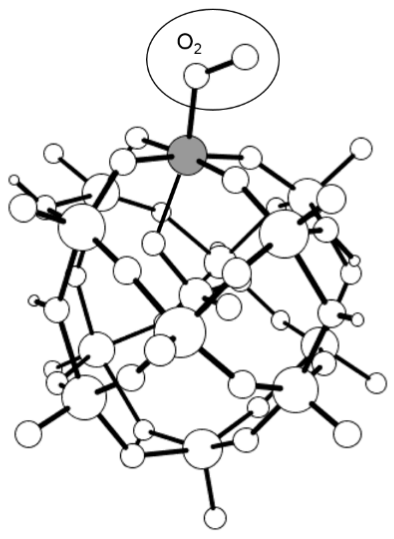

$\mathrm{HPW}_{11} \mathrm{Co}-\mathrm{OO} / \mathrm{HPMo}_{11} \mathrm{Co}-\mathrm{OO}$

Figure 1. The geometric structure of complexes were obtained as a result of the molecular oxygen interaction with the studied systems: OO- $\mathrm{Co}\left(\mathrm{H}_{2} \mathrm{O}\right)_{5}{ }^{2+}(\mathbf{a}), \mathrm{OO}-\mathrm{Co}\left(\mathrm{CH}_{3} \mathrm{CN}\right)_{6}{ }^{2+}(\mathbf{b})$, and $\mathrm{HPW}(\mathrm{Mo})_{11} \mathrm{Co}-\mathrm{OO}(\mathbf{c})$.

Table 1. The energetic (binding energy $\Delta \mathrm{E}_{\mathrm{B}}[\mathrm{kJ} / \mathrm{mol}]$ for the reactions (1-3)), geometric (bond length $\mathrm{d}(\mathrm{Co}-\mathrm{O} / \mathrm{O}-\mathrm{O})[\AA]$ ) and electronic (Mayer bond order indexes $\mathrm{BO}$ ) parameters characterize the bond between the metallic center $\left(\mathrm{Co}^{2+}\right)$ and the oxygen molecule.

\begin{tabular}{ccccc}
\hline System & $\mathbf{C o}\left(\mathbf{H}_{\mathbf{2}} \mathbf{O}_{\mathbf{5}^{2+}}{ }^{2+}\right.$ & $\mathbf{C o}\left(\mathbf{C H}_{\mathbf{3}} \mathbf{C N}\right)_{5}{ }^{2+}$ & HPW $_{\mathbf{1 1}}$ Co & HPMo Co $^{\text {Co }}$ \\
\hline$\Delta \mathrm{E}_{\mathrm{B}}$ & -30.15 & -32.61 & -53.62 & -51.07 \\
$\mathrm{~d}(\mathrm{Co}-\mathrm{O})$ & 2.09 & 2.06 & 1.92 & 1.94 \\
$\mathrm{BO}(\mathrm{Co}-\mathrm{O})$ & 0.64 & 0.63 & 0.80 & 0.78 \\
$\mathrm{~d}(\mathrm{O}-\mathrm{O})$ & 1.22 & 1.24 & 1.25 & 1.25 \\
$\mathrm{BO}(\mathrm{O}-\mathrm{O})$ & 1.48 & 1.50 & 1.40 & 1.41 \\
\hline
\end{tabular}

Binding energy, presented in Table 1 (first row), shows that all studied systems exhibit the ability to adsorb molecular oxygen. The calculated $\mathrm{E}_{\mathrm{B}}$ values show that adsorption of the $\mathrm{O}_{2}$ molecule is more 
energy efficient on cobalt cation introduced in tungsten/molybdenum Keggin anions than in the cobalt cation surrounded by both (water/acetonitrile) types of solvent molecules.

In all systems, molecular oxygen adsorbs on the cobalt center in a side-on geometry, and the result of this adsorption is that the formation of a single $\mathrm{Co}-\mathrm{O}$ bond is observed. Bond lengths are smaller (equal 1.92/1.94 [̊̊]) between oxygen and cobalt built-in tungsten/molybdenum Keggin anions than between oxygen and cobalt surrounded by water/acetonitrile solvent molecules (equal 2.09/2.06 [ $\AA$ ], respectively). The calculated bond order index values (equal 0.8) suggest the formation of a stronger $\mathrm{Co}-\mathrm{O}$ bond in $\mathrm{HPW}(\mathrm{Mo})_{11} \mathrm{Co}-\mathrm{OO}$ than in $\mathrm{Co}\left(\mathrm{H}_{2} \mathrm{O}\right)_{5}{ }^{2+}$ and $\mathrm{Co}\left(\mathrm{CH}_{3} \mathrm{CN}\right)_{5}{ }^{2+}$ systems (where $\mathrm{BO}$ are equal about 0.6).

The comparison of the geometric and electronic parameters allows for the characterization of the isolated $\mathrm{O}_{2}$ molecule $(\mathrm{d}=1.22[\AA], \mathrm{BO}=1.72)$, with values obtained after adsorption to the cobalt center, which clearly indicates that adsorption leads to oxygen activation. The interaction of the $\mathrm{O}_{2}$ molecule with the $\mathrm{Co}^{2+}$ results in the elongation and weakening of the O-O bond. The O-O bond length changes from 1.22 in the isolated $\mathrm{O}_{2}$ molecule to $1.25[\AA]$, following adsorption of the $\mathrm{Co}^{2+}$ built-in Keggin anion and $1.24 \AA$, following adsorption on $\mathrm{Co}^{2+}$ coordinated with acetonitrile molecules. Adsorption at the metal center goes to weakening of the O-O bonds, observed as a lowering of the Mayer bond order indexes (from the value of 1.75 in the isolated molecule to 1.40 in the $\mathrm{HPW}_{11} \mathrm{Co}$ and $\mathrm{HPMo}_{11} \mathrm{Co}$ and ca. 1.50 in the $\mathrm{Co}\left(\mathrm{H}_{2} \mathrm{O}\right)_{5}{ }^{2+}$ and $\mathrm{Co}\left(\mathrm{CH}_{3} \mathrm{CN}\right)_{5}{ }^{2+}$ systems, respectively).

Is the mechanism of activation the same for all studied systems? To answer this question, the NOCV method, carried out at a spin resolution (SR), was used. All the studied systems had to be divided into two fragments, between which of the $\mathrm{Co}-\mathrm{OO}$ bonds are formed. The first fragment contained the cobalt cation with its geometric environment $\left(\mathrm{HPW}_{11} \mathrm{Co} / \mathrm{HPMo}_{11} \mathrm{Co}\right.$ Keggin anions and $\mathrm{Co}\left(\mathrm{H}_{2} \mathrm{O}\right)_{5}{ }^{2+} / \mathrm{Co}\left(\mathrm{CH}_{3} \mathrm{CN}\right)_{5}{ }^{2+}$ complexes), and the second contained the oxygen molecule $(\mathrm{O}-\mathrm{O})$. Defining the multiplicity of all fragments and the whole system was another step taken prior to performing the NOCV-SR (Natural Orbitals for Chemical Valence in Spin Resolution) analysis. Taking into consideration the abovementioned calculations, it was stated that multiplicity for every cobalt-containing fragment is 2 (before and after adsorption of $\mathrm{O}_{2}$ ) and the multiplicity of the oxygen molecule is a triplet (oxygen molecule behaves as paramagnetic).

We begin the discussion with the $\mathrm{Co}\left(\mathrm{H}_{2} \mathrm{O}\right)_{5}{ }^{2+}-\mathrm{OO}$ complex. Figure 2 presents four $(2 \mathrm{a}, \mathrm{b}, \mathrm{d}, \mathrm{e})$ NOCV contours, describing the bond between the cobalt cation and $\mathrm{O}-\mathrm{O}$ ligand in the $\mathrm{Co}\left(\mathrm{H}_{2} \mathrm{O}\right)_{5}{ }^{2+}-\mathrm{OO}$ complex. Considering that NOCV can be grouped in pairs of complementary orbitals, corresponding to the same eigenvalue with the opposite sign [53], the Co-OO bond can be described by two (2a2b and 2d2e) pairs of complementary NOCVs.

As shown in Figure 2, both pairs $\left(\phi_{1 \alpha} \phi-1 \alpha\right.$ and $\left.\phi_{1 \beta} \phi-1 \beta\right)$ exhibit $\sigma$ character, and each NOCV contains a contribution from both fragments $\left(\mathrm{Co}\left(\mathrm{H}_{2} \mathrm{O}\right)_{5}{ }^{2+}\right.$ and $\mathrm{OO}$ molecule). Generally, all NOCVs are built from anti-bonding $\left(\pi^{*}\right)$ oxygen orbitals and $3 \mathrm{~d}$ orbitals from the cobalt atom as well as the $2 p$ orbitals of oxygen atoms from water molecules. The orbitals $\phi-1 \alpha$ and $\phi-1 \beta$ exhibit anti-bonding characteristics, whereas the second orbital pairs are clearly a $\sigma$-bonding orbital, localized predominantly in the bond region. The contribution from the first pair of orbitals to the deformation density, $\Delta_{1}{ }^{\alpha} \rho(\mathrm{r})$ (Figure 2c), clearly shows that this pair of orbitals participates in the process of donation from the O-O molecule to the cobalt complex. Analysis of eigenvalues shows that oxygen losses are $0.74 \mathrm{e}$, while the cobalt complex gains $0.74 \mathrm{e}$ in this process. In contrast, the contributions from the second pair of complementary NOCVs to the deformation density $\Delta_{1} \beta \rho(r)$ (Figure 2f), corresponds to the backdonation process from the $\mathrm{Co}\left(\mathrm{H}_{2} \mathrm{O}\right)_{5}{ }^{2+}$ complex to the $\mathrm{O}_{2}$ molecule. The second pair $\left(\phi_{1 \beta} \phi_{-1 \beta}\right)$ is characterized by $|v|=0.76$ and describes the process of 0.76 electron inflow to antibonding oxygen orbitals. 
NOCV

a) $\varphi_{1 \alpha}$

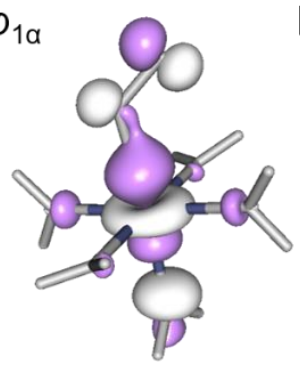

b) $\varphi_{-1 \alpha}$

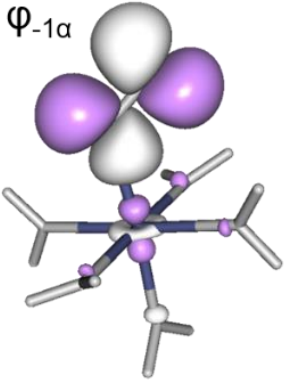

deformation density

c) $\Delta_{1}{ }^{\alpha} \rho(r)$

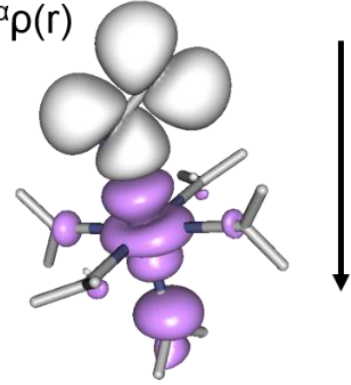

$\sigma$ donation

d) $\varphi_{1 \beta}$

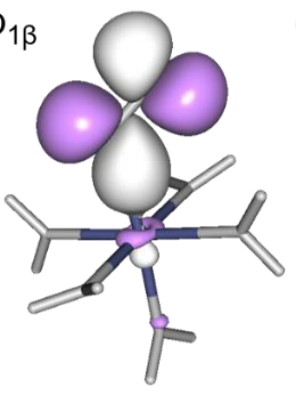

e) $\varphi_{-1 \beta}$

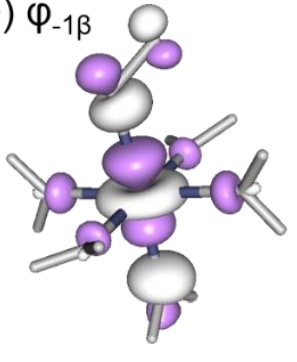

f) $\Delta_{1}^{\beta} \rho(r)$

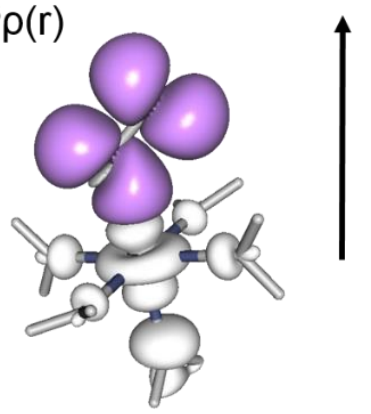

$\sigma$ backdonation

Figure 2. NOCV (pair for $\alpha$ electrons $(\mathbf{a}, \mathbf{b})$ and for $\beta$ electrons $(\mathbf{d}, \mathbf{e})$ ) and the contribution to the deformation density $\Delta \rho(\mathrm{r})(\mathbf{c}, \mathbf{f})$ originated from the pairs complementary to NOCV, characterizing the bond between the $\mathrm{Co}\left(\mathrm{H}_{2} \mathrm{O}\right)_{5}{ }^{2+}$ fragment and $\mathrm{OO}$ ligand. The $|\Delta \rho|=0.05$ a.u. contours are shown. White orbitals describe the outflow, and purple, the inflow of electrons.

Identical analysis was carried out for the $\mathrm{Co}\left(\mathrm{CH}_{3} \mathrm{CN}\right)_{5}{ }^{2+}-\mathrm{OO}$ system (Figure 3). Similar to the previous system, the bond between the cobalt complex and oxygen molecule describes the two pairs of complementary NOCV (Figure 3a,b,d,e), both $\left(\phi_{1 \alpha} \phi-1 \alpha\right.$ and $\left.\phi_{1 \beta} \phi-1 \beta\right)$ with $\sigma$ symmetry. The first pair $\left(\phi_{1 \alpha} \phi-1 \alpha\right)$ describes the transfer from the oxygen ligand to the cobalt complex, whereas the second pair $\left(\phi_{1 \beta} \phi_{-1 \beta}\right)$ of NOCV participates in the backdonation process, in which electrons transfer from the cobalt complex to the anti-bonding oxygen orbitals. The obtained eigenvalues $(|v|=0.40$ characterize the donation process (Figure 3c) and $|v|=0.51$ for backdonation (Figure 3f)) show that the backdonation process is predominated in the overall deformation density $\Delta \rho(\mathrm{r})$. Detailed analysis of NOCV contours show that not only the oxygen atom and metal ion participate in the formation of $\mathrm{Co}-\mathrm{O}$ bond, but also nitrogen atoms from acetonitryle solvent molecules.

Preliminary analysis of the $\mathrm{HPW}_{11} \mathrm{Co}-\mathrm{O}_{2}$ and $\mathrm{HPMo}_{11} \mathrm{Co}-\mathrm{O}_{2}$ systems show that the quality description of the interaction between the $\mathrm{O}_{2}$ molecule with cobalt-modified tungsten and molybdenum heteropolyacids is identical. Thus, Figure 4 presents the contours of NOCV and the contribution to the deformation density for both $\mathrm{W}(\mathrm{Mo})$ Co systems, while the differentiating electron flow data are given in Table 2. 
NOCV

a) $\varphi_{1 \alpha}$

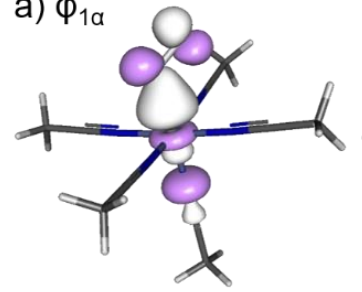

b) $\varphi_{-1 \alpha}$

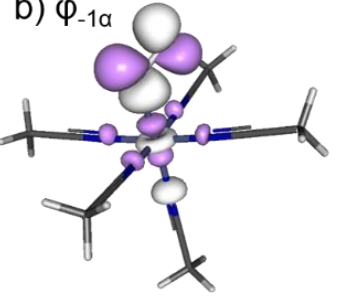

d) $\varphi_{1 \beta}$

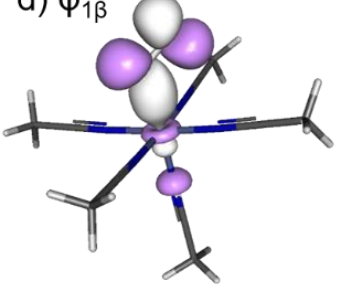

e) $\varphi_{-1 \beta}$

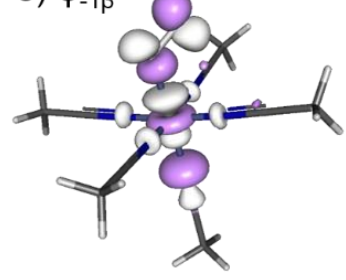

deformation density

c) $\Delta_{1}{ }^{a} \rho(r)$

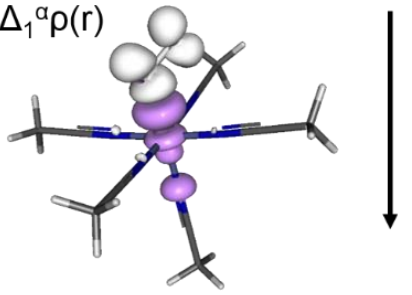

$\sigma$ donation

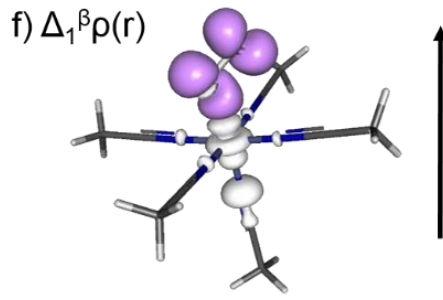

$\sigma$ backdonation

Figure 3. NOCV (pair for $\alpha$ electrons $(\mathbf{a}, \mathbf{b})$ and for $\beta$ electrons $(\mathbf{d}, \mathbf{e})$ ) and contribution to the deformation density $\Delta \rho(\mathrm{r})(\mathbf{c}, \mathbf{f})$ originated from the pairs of complementary of NOCVs, characterizing the bond between the $\mathrm{Co}\left(\mathrm{CH}_{3} \mathrm{CN}\right)_{5}{ }^{2+}$ fragment and $\mathrm{OO}$ ligand. The $|\Delta \rho|=0.05$ a.u. contours are shown. White orbitals describe the outflow, and purple describes the inflow of electrons.

NOCV

a) $\varphi_{1 \alpha}$

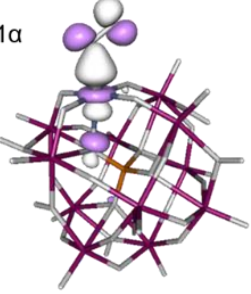

d) $\varphi_{1 \beta}$

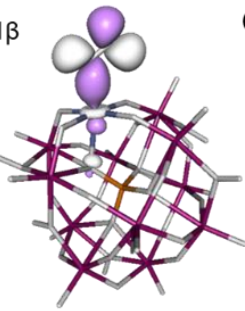

g) $\varphi_{2 \beta}$

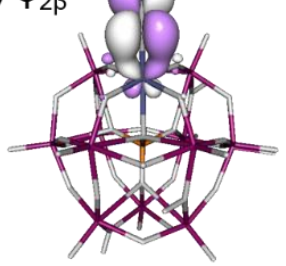

b) $\varphi_{-1 a}$

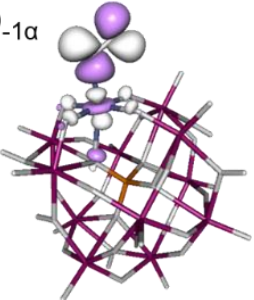

e) $\varphi_{-1 \beta}$

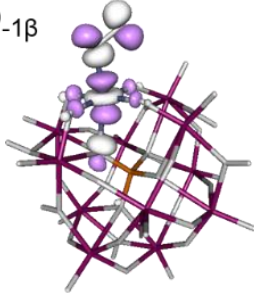

h) $\varphi_{-2 \beta}$

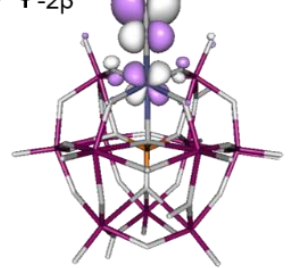

\section{deformation density}

c) $\Delta_{1}{ }^{\alpha} \rho(r)$

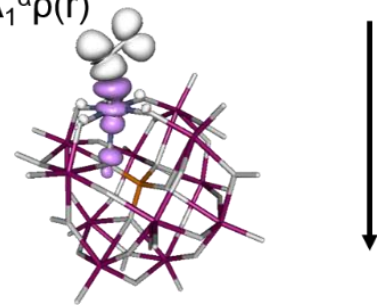

\section{$\sigma$ donation}

f) $\Delta_{1}{ }^{\beta} p(r)$
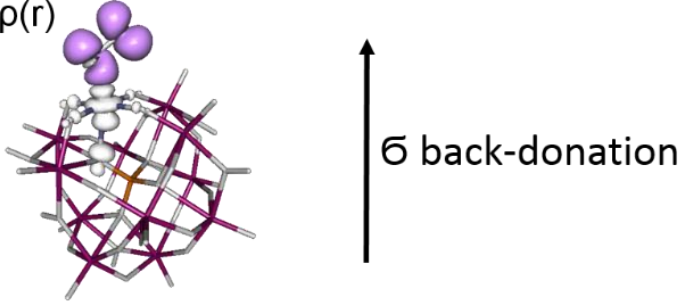

i) $\Delta_{2}^{\beta} \rho(r)$

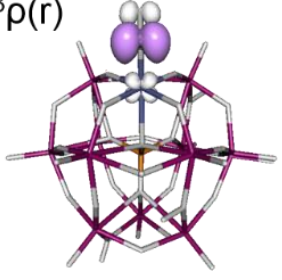

$\pi$ polarization

Figure 4. NOCV(pair for $\alpha$ electrons $(\mathbf{a}, \mathbf{b})$ and for $\beta$ electrons $(\mathbf{d}, \mathbf{e}, \mathbf{g}, \mathbf{h}))$ and the contribution to the deformation density $\Delta \rho(\mathrm{r})(\mathbf{c}, \mathbf{f}, \mathbf{i})$ originated from the pairs of complementary of NOCV, characterizing the bond between the $\operatorname{HPW}(\mathrm{Mo}){ }_{11} \mathrm{Co}$ fragment and $\mathrm{OO}$ ligand. The $|\Delta \rho|=0.05$ a.u. contours are shown. White orbitals describe the outflow, and purple describes the inflow of electrons. 
Table 2. NOCV-eigenvalues describe the $\sigma$-donation, $\sigma$-backdonation, and $\pi$-polarization processes observed as a result of the interaction between the studied systems and the $\mathrm{O}_{2}$ molecule.

\begin{tabular}{|c|c|c|c|c|}
\hline System & $\mathrm{Co}\left(\mathrm{H}_{2} \mathrm{O}\right)_{5}{ }^{2+}$ & $\mathrm{Co}\left(\mathrm{CH}_{3} \mathrm{CN}\right)_{5}{ }^{2+}$ & $\mathrm{HPW}_{11} \mathrm{Co}$ & $\mathrm{HPMo}_{11} \mathrm{Co}$ \\
\hline$\sigma$ donation & 0.74 & 0.40 & 0.49 & 0.46 \\
\hline$\sigma$ backdonation & 0.76 & 0.51 & 0.56 & 0.57 \\
\hline$\sigma$ backdonation $-\sigma$ donation & 0.02 & 0.11 & 0.07 & 0.11 \\
\hline$\pi$ polarization of $\mathrm{O}-\mathrm{O}$ & - & - & 0.24 & 0.21 \\
\hline
\end{tabular}

In contrast to the presented cobalt complexes, the bond between molecular oxygen and $\mathrm{HPW}_{11} \mathrm{Co} /$ $\mathrm{HPMo}_{11}$ Co systems is described by three pairs, which are complementary to NOCVs. Two pairs $\left(\phi_{1 \alpha} \phi-1 \alpha\right.$ and $\left.\phi_{1 \beta} \phi-1 \beta\right)$ exhibit $\sigma$ character, whereas the third one $\left(\phi_{2 \beta} \phi-2 \beta\right)$ is characterized by orbitals with $\pi$ symmetry. As shown in Figure 4 , the formation of the $\mathrm{Co}-\mathrm{OO}$ bond participates not only the orbitals of adsorbed $2 p$ oxygen and $3 d$ cobalt orbitals but also the $2 p$ orbitals of the oxygen atoms from the Keggin framework (the orbitals of internal (Oa) and bridging (Ob, Oc) oxygen atoms). Detailed analysis of NOCV contributions to the deformation density shows that orbitals from the first pair of NOCVs participate in donation from adsorbed $\mathrm{O}_{2}$ to the Keggin anion, where the cobalt cation is introduced. The negative contribution (outflow of electrons) is localized on the oxygen orbitals, and positive changes (increase in the number of electrons) are visible on the Keggin anion (primarily on the cobalt cation and its surroundings). The second pair of NOCV describes the backdonation process, in which electrons flow from the Keggin anion to the ligand orbitals (adsorbed molecular oxygen). The third active electron channel shows the internal polarization inside the adsorbed oxygen molecules, which can be described as a $\pi$ donation from the Keggin skeleton to the oxygen molecule. Calculated eigenvalues describe the electron flow between two defined fragments $\left(\mathrm{HPW}_{11} \mathrm{Co} / \mathrm{HPMo}_{11} \mathrm{Co}\right.$ and the $\mathrm{O}-\mathrm{O}$ molecule), the result of which is the creation of the $\mathrm{Co}-\mathrm{OO}$ bond, as seen from Table 2. Calculated data are very similar for both tungsten and molybdenum systems.

The data presented in Table 2 clearly show that, in all studied systems, the formation of the Co-OO bond is the result of several processes, in which two processes dominated: (a) The donation from ligand to the metal center, and (b) the backdonation from metal to the oxygen ligand. Interaction between the oxygen molecule and cobalt center, introduced in the Keggin anion, is additionally supported by polarization inside the oxygen molecule. The obtained eigenvalues show that the sum of the electron flow in donation and backdonation processes are similar for all studied systems, except for the water complex $\mathrm{Co}\left(\mathrm{H}_{2} \mathrm{O}\right)_{5}{ }^{2+}$. Another parameter differentiating the systems is the observed polarization in $\mathrm{HPW}_{11} \mathrm{Co}$ and $\mathrm{HPMo}_{11}$ Co systems.

Activation of the oxygen molecule, observed in NOCV analysis, can be confirmed by calculations of the IR spectra. The values of stretching $\mathrm{O}-\mathrm{O}$ bond frequencies, before and after adsorption on the cobalt center, in different geometrical surroundings, were analyzed. The obtained values are presented in Table 3.

Table 3. The difference (redshift) between the vibration wave number $\left[\mathrm{cm}^{-1}\right]$ of $\mathrm{O}-\mathrm{O}$ bond in the $\mathrm{O}_{2}$ molecule, before and after adsorption of $\mathrm{O}_{2}$ on the cobalt center in the studied systems.

\begin{tabular}{ccccc}
\hline System & $\mathrm{Co}\left(\mathrm{H}_{\mathbf{2}} \mathbf{O}\right)_{5}{ }^{2+}$ & $\mathrm{Co}\left(\mathrm{CH}_{3} \mathrm{CN}\right)_{5}{ }^{2+}$ & HPW $_{11} \mathrm{Co}$ & HPMo $_{11}$ Co \\
\hline Redshift & 96.40 & 179.37 & 203.77 & 205.59 \\
\hline
\end{tabular}

In all cases, the lowering of the stretching $\mathrm{O}-\mathrm{O}$ bond frequencies was observed in the direction of longer wavelengths (redshift), relative to the position defined for the isolated $\mathrm{O}_{2}$ molecule $\left(1555 \mathrm{~cm}^{-1}\right)$. The obtained values show that the strongest $\mathrm{O}-\mathrm{O}$ activation (the largest redshift) is observed for the $\mathrm{Co}^{2+}$ cation built into the Keggin heteropolyacid. The values obtained for tungsten and molybdenum system are close to each other (redshift in HPMoCo is slightly bigger than in the case of HPWoCo). The weakest activation is observed after adsorption of $\mathrm{O}_{2}$ on the $\mathrm{Co}^{2+}$ cation in water complexes. The obtained data 
confirmed, (obtained using the NOCV analysis theoretical parameters such as bond length and bond orders), that the activation of oxygen molecule adsorbed on $\mathrm{Co}^{2+}$, built into the Keggin heteropolyacid, is stronger than after adsorption on $\mathrm{Co}^{2+}$ complexes with solvent (water/acetonitrile) molecules. The obtained results, by differentiating the $\mathrm{Co}\left(\mathrm{CH}_{3} \mathrm{CN}\right)_{5}{ }^{2+}$ and $\mathrm{HPW}_{11} \mathrm{Co} / \mathrm{HPW}_{11}$ Co systems (for which almost identical electron flow values were obtained in the donation and backdonation processes) indicate the role of the polarization process, which was only observed in systems with cobalt cation embedded in the Keggin anion.

\section{Methods}

The oxidation ability of the $\mathrm{Co}^{2+}$ cation was investigated with the DFT (Density Functional Theory) method (package Turbomole) [54] using a cluster model. The exchange and correlation energies were calculated using the Becke-Perdew-Ernzerhof (PBE) functional [55-57], where all electron basis sets of def-TZVP quality were used. The relativistic effects are already noticeable for post $3 \mathrm{~d}$ elements; therefore, it is better to use effective core potentials (ECPs) with relativistic corrections, instead of all electron basis sets [58]. The resolution of identity (RI) approach was applied for computing the electronic Coulomb interactions [59,60]. For all studied species, the calculations were performed for all possible spin states, and the one with the lowest energy was chosen for further investigation.

All structures were optimized as a spin unrestricted open-shell system. Geometry optimization was performed in accordance with the quasi-Newton-Raphsod method [61]. Geometry was considered converged for the following conditions: (a) The energy change between two optimization cycles drops below $10^{-6}$ a.u., (b) the maximum displacement element drops below $10^{-3}$ a.u., and the maximum gradient element drops below $10^{-3}$ a.u.

To characterize the process of bond formation between the metallic center $\left(\mathrm{Co}^{2+}\right)$ and oxygen molecule, Natural Orbital Chemical Valences in Spin Resolution (NOCV-SR) was performed [53,62-64]. Natural orbitals for the chemical valence were defined as the eigenvectors of the chemical valence operator of the Nalewajski-Mrozek theory:

$$
\mathrm{V} \varphi_{\mathrm{i}}=v \varphi_{\mathrm{i}} \quad \mathrm{I}=1 \ldots \mathrm{N}
$$

with the valence operator given by a matrix

$$
\mathrm{V}=1 / 2 \Delta \mathrm{P}
$$

where $\Delta \mathrm{P}$ corresponds to a difference between the charge-and-bond-order matrices of a molecule and promolecule (set of isolated atoms, or molecular fragments, ligands, etc.).

It has been found that NOCV leads to a very compact description of the fragment-ligand bond, with only a few orbitals exhibiting non-zero eigenvalues. The results of the NOCV analysis allow for the separation of the $\sigma, \pi$ donation, and backdonation contributions to the ligand-fragment bond. They can also be useful in the comparison of these contributions in different complexes.

For theoretical modeling, three geometric structures (see Figure $5 \mathrm{a}-\mathrm{c}$ ) were taken into consideration. The first two geometries (see Figure $5 \mathrm{a}, \mathrm{b}$ ) represent a simplified structure, in which the cation is surrounded by five solvent $\left(\mathrm{H}_{2} \mathrm{O}\right.$ or $\left.\mathrm{CH}_{3} \mathrm{CN}\right)$ molecules, creating the $\mathrm{Co}\left(\mathrm{H}_{2} \mathrm{O}\right)_{5}{ }^{2+}$ and $\mathrm{Co}\left(\mathrm{CH}_{3} \mathrm{CN}\right)_{5}{ }^{2+}$ complexes, with a total charge equal to +2 (as a result of the $\mathrm{Co}^{2+}$ charge and neutral water/acetonitrile molecules). Both models were used to show the influence of the solvent environment on the oxidation ability of $\mathrm{Co}^{2+}$ in the system, where the cobalt cation plays the role of a counter cation. The third geometry (Figure 5c) presents the Keggin anion, where one of the tungsten or molybdenum atoms (W/Mo), from the anion framework, was replaced by the $\mathrm{Co}^{2+}$ cation. This model represents the $\mathrm{H}_{5} \mathrm{PW}_{11} \mathrm{CoO}_{39}$ (referred as a $\mathrm{HPW}_{11} \mathrm{Co}$ ) and $\mathrm{H}_{5} \mathrm{PMo}_{11} \mathrm{CoO}_{39}$ (referred as a $\mathrm{HPMo}_{11} \mathrm{Co}$ ) systems, modified in the addenda atom position. The total charge of that modified heteropolyacid is zero, since the global heteropolyanion charge $(-5)$ was compensated by 5 hydrogen atoms. This model may show how the properties of $\mathrm{Co}^{2+}$ depend on the chemical composition (tungsten/molybdenum) of the 
Keggin anion. The comparison of the models, with each other, allows for the determination of the effect of geometry on cobalt's ability to adsorb and activate oxygen molecule.

(a)

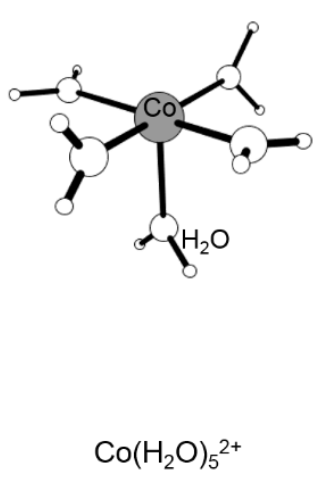

(b)

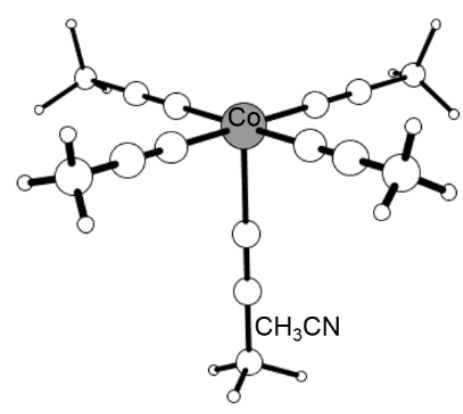

$\mathrm{Co}\left(\mathrm{CH}_{3} \mathrm{CN}\right)_{5}^{2+}$ (c)

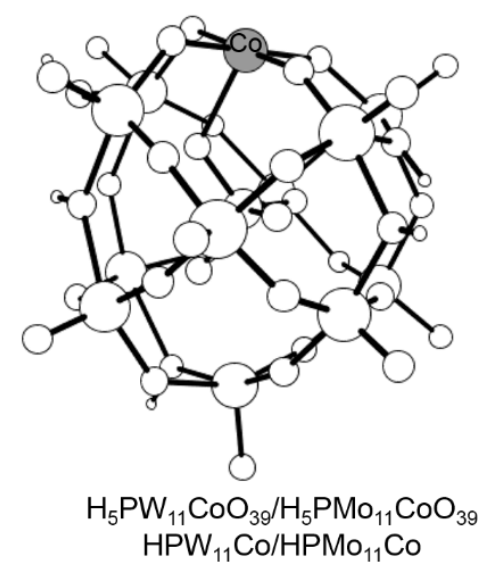

Figure 5. Structure of studied systems: Co-water complex (a), co-acetonitrile complex (b), and tungsten/ molybdenum Keggin anion with cobalt introduced as one addenda atom (c).

\section{Conclusions}

This article examines the chemical environmental role in the oxidizing capacity of $\mathrm{Co}^{2+}$ located in different geometrical environments. For this purpose, $\mathrm{H}_{5} \mathrm{PMo}_{11} \mathrm{CoO}_{39}, \mathrm{H}_{5} \mathrm{PW}_{11} \mathrm{CoO}_{39}, \mathrm{Co}\left(\mathrm{H}_{2} \mathrm{O}\right)_{5}{ }^{2+}$, and $\mathrm{Co}\left(\mathrm{CH}_{3} \mathrm{CN}\right)_{5}{ }^{2+}$ systems were examined.

It has been shown that both the adsorption and activation process of the molecular oxygen molecule depend on the environment in which the cobalt is found. Adsorption energy for bonding $\mathrm{O}_{2}$ onto the $\mathrm{Co}^{2+}$ center is much higher in the case of the modified heteropolyacids systems $\left(\mathrm{H}_{5} \mathrm{PMo}_{11} \mathrm{CoO}_{39}, \mathrm{H}_{5} \mathrm{PW}_{11} \mathrm{CoO}_{39}\right)$ than in complexes with solvent molecules $\left(\mathrm{Co}\left(\mathrm{H}_{2} \mathrm{O}\right)_{5}{ }^{2+}\right.$ and $\left.\mathrm{Co}\left(\mathrm{CH}_{3} \mathrm{CN}\right)_{5}{ }^{2+}\right)$. Both electronic (bond order) and geometrical (bond length) parameters imply that the activation process of the oxygen molecule is stronger in the molybdenum and tungsten modified heteropolyacids $\left(\mathrm{H}_{5} \mathrm{PMo}_{11} \mathrm{CoO}_{39}, \mathrm{H}_{5} \mathrm{PW}_{11} \mathrm{CoO}_{39}\right)$ than in both solvated systems $\left(\mathrm{Co}\left(\mathrm{H}_{2} \mathrm{O}\right)_{5}{ }^{2+}\right.$ and $\left.\mathrm{Co}\left(\mathrm{CH}_{3} \mathrm{CN}\right)_{5}{ }^{2+}\right)$.

Detailed NOCV-SR analysis shows that, for all studied systems, the $\sigma$-donation and $\sigma$-backdonation active channels of electron transfer are responsible for the creation of a single $\mathrm{Co}-\mathrm{OO}$ bond and the activation of the oxygen molecule. Depending on the chemical/geometrical environment of the $\mathrm{Co}^{2+}$ cation, different quantities of electrons are flown from the $3 \mathrm{~d}$ cobalt orbitals to the $\pi^{*}$ antibonding molecular orbitals, as well as in the opposite direction. In the modified molybdenum and tungsten heteropolyacids, activation of the $\mathrm{O}_{2}$ molecule is supported by a $\pi$-polarization process.

The calculated redshift values confirmed that the ability of $\mathrm{Co}^{2+}$ ion for adsorption and activation of the oxygen molecule changes in the following order: $\mathrm{H}_{5} \mathrm{PMo}_{11} \mathrm{CoO}_{39}=\mathrm{H}_{5} \mathrm{PW}_{11} \mathrm{CoO}_{39}>\mathrm{Co}\left(\mathrm{CH}_{3} \mathrm{CN}\right)_{5}{ }^{2+}$ $>\mathrm{Co}\left(\mathrm{H}_{2} \mathrm{O}\right)_{5}{ }^{2+}$. The obtained theoretical results show that the cobalt cation acts as an addenda atom (introduced in the primary structure of HPA), which is more likely to activate the molecular oxygen molecule than a compensating cation (in the secondary structure of HPA, in the solvent environment). The process of oxygen activation is easier when oxygen is adsorbed on the cobalt center introduced into the Keggin anion, where the large environment of the metal center may create a reservoir of electron outflow/inflow.

Author Contributions: Conceptualization, R.T.-S.; Data curation, P.N.; Formal analysis, R.T.-S. and P.N.; Investigation, R.T.-S.; Methodology, R.T.-S. and P.N.; Supervision, R.T.-S.; Visualization, P.N.; Writing一original draft, R.T.-S. and P.N.; Writing—review \& editing, R.T.-S. All authors have read and agreed to the published version of the manuscript. 
Funding: This research was done within the statutory funds of the Jerzy Haber Institute of Catalysis and Surface Chemistry, Polish Academy of Sciences.

Conflicts of Interest: The authors declare no conflict of interest.

\section{References}

1. Pope, M.T. Heteropoly and Isopoly Oxometalates; Springer: New York, NY, USA, 1983.

2. Kozhevnikov, I.V. Catalysis by polyoxometalates. In Catalysts for Fine Chemical Synthesis; John Wiley and Sons Ltd.: Hoboken, NJ, USA; The Atrium: Chichester, UK, 2002; Volume 2.

3. Misono, M. Heterogeneous Catalysis by Heteropoly Compounds of Molybdenum and Tungsten. Catal. Rev. Sci. Eng. 1987, 29, 269-321. [CrossRef]

4. Timofeeva, M.N. Acid Catalysis by Heteropoly Acids. Appl. Catal. A Gen. 2003, 256, 19-35. [CrossRef]

5. Sun, M.; Zhang, J.; Putaj, P.; Caps, V.; Lefebvre, F.; Pelletier, J.; Basset, J.M. Catalytic Oxidation of Light Alkanes (C1-C4) by Heteropoly Compounds. Chem. Rev. 2014, 114, 981-1019. [CrossRef] [PubMed]

6. Oms, O.; Delbecq, A.; Mialane, P. Diversity in structures and properties of 3d-incorporating polyoxotungstates. Chem. Soc. Rev. 2012, 41, 7497-7536. [CrossRef] [PubMed]

7. Shikata, S.; Okuhara, T.; Misono, M. Catalysis by hetropoly compounds. Part XXVI. Gas phase synthesis of methyl tert-butyl ether over heteropolyacids. J. Mol. Catal. A Chem. 1995, 100, 49-59. [CrossRef]

8. Hu, C.; Hashimoto, M.; Okuhara, T.; Misono, M. Catalysis by Heteropoly Compounds. XXII. Reactions of Esters and Esterification Catalyzed by Heteropolyacids in a Homogeneous Liquid-Phase Effects of the Central Atom of Heteropolyanions Having Tungsten as the Addenda Atom. J. Catal. 1993, 143, 437-448. [CrossRef]

9. Habibi, M.H.; Tangestaninejad, S.; Mirkhani, V.; Yadollahi, B. Catalytic Acetylation of Alcohols and Phenols with Potassium Dodecatungstocobaltate Trihydrate. Monatshefte Chemie 2002, 133, 323-327. [CrossRef]

10. Habibi, M.H.; Tangestaninejad, S.; Mohammadpoor-Baltork, I.; Mirkhani, V.; Yadollahi, B. Potassium Dodecatangestocobaltate Trihydrate $\left(\mathrm{K}_{5} \mathrm{CoW}_{12} \mathrm{O}_{40} \cdot 3 \mathrm{H}_{2} \mathrm{O}\right)$ : A Mild and Efficient Catalyst for the Tetrahydropyranylation of Alcohols and their Detetrahydropyranylation. Tetrahedron Lett. 2001, 42, 2851-2853. [CrossRef]

11. Tangestaninejad, S.T.; Moghadam, M.; Mirkhani, V.; Yadollahi, B.; Mohammad, S.; Mirmohammadi, R. Mild and Efficient Ring Opening of Epoxides Catalyzed by Potassium Dodecatungstocobaltate(III). Monatshefte Chemie 2006, 137, 235-242. [CrossRef]

12. Habibi, M.H.; Tangestaninejad, S.T.; Mirkhani, V.; Yadollahi, B. $\mathrm{K}_{5} \mathrm{CoW}_{12} \mathrm{O}_{40} \cdot 3 \mathrm{H}_{2} \mathrm{O}$ : A Novel Cobalt Polyoxometalate Catalyst for Conversion of Epoxides to Acetonides. Catal. Lett. 2001, 75, 205-207. [CrossRef]

13. Nakajima, K.; Eda, K.; Himeno, S. Effect of the Central Oxoanion Size on the Voltammetric Properties of Keggin-Type $\left[\mathrm{XW}_{12} \mathrm{O}_{40}\right]^{\mathrm{n}-}(\mathrm{n}=2-6)$ Complexes. Inorg. Chem. 2010, 49, 5212-5215. [CrossRef] [PubMed]

14. Gao, G.G.; Xu, L.; Wang, W.J.; Qu, X.S.; Liu, H.; Yang, Y.Y. Cobalt (II)/nickel (II)-centered Keggin-type heteropolymolybdates: Syntheses, crystal structures, magnetic and electrochemical properties. Inorg. Chem. 2008, 47, 2325-2333. [CrossRef] [PubMed]

15. Song, I.K.; Bertau, M.A. Redox properties of keggin-type heteropolyacid (HPA) catalysts: Efect of counter-cation, heteroatom, and polyatom substitution. J. Mol. Catal. A Chem. 2004, 212, $229-236$. [CrossRef]

16. Maradur, S.P.; Gokavi, G.S.; Selvam, P. Poly (Vinyl Alcohol) Supported 12-Tungstocobaltate (II) as a Novel Heterogeneous Catalyst for Oxidation of Benzyl Alcohols. Bull. Catal. Soc. India 2007, 6, 42-49.

17. Simoes, M.M.Q.; Conceicao, C.M.M.; Gamelas, J.A.F.; Domingues, P.M.D.N.; Cavaleiro, A.M.V.; Cavaleiro, J.A.S.; Ferrer-Correia, A.J.V.; Johnstone, R.A.W. Keggin-type polyoxotungstates as catalysts in the oxidation of cyclohexane by dilute aqueous hydrogen peroxide. J. Mol. Catal. A Chem. 1999, 144, 461-468. [CrossRef]

18. Trakarnpruk, W. Heterogeneous Catalytic Oxidation of Cyclohexane with $\mathrm{H}_{2} \mathrm{O}_{2}$ Catalyzed by Cs- and TBA-salts of Cu- and Mn-Polyoxotungstates on MCM-41. Int. J. Chem. Eng. Appl. 2015, 6, 120-124. [CrossRef]

19. Choi, J.H.; Kim, J.K.; Park, D.R.; Kang, T.H.; Song, J.H.; Song, I.K. Redox properties and oxidation catalysis of transition metal-substituted $\alpha-\mathrm{K}_{5} \mathrm{PW}_{11} \mathrm{O}_{39}\left(\mathrm{M} \cdot \mathrm{OH}_{2}\right)\left(\mathrm{M}=\mathrm{Mn}^{\mathrm{II}}, \mathrm{Co}^{\mathrm{II}}, \mathrm{Ni}{ }^{\mathrm{II}}\right.$, and $\left.\mathrm{Zn}^{\mathrm{II}}\right)$ Keggin heteropolyacid catalysts for liquid-phase oxidation of 2-propanol. J. Mol. Catal. A Chem. 2013, 371, 111-117. [CrossRef] 
20. Guangdong, Z.; Zhalin, X.; Xiaohong, G.; Hong, Z.; Yanan, L.; Xueju, L.; Tiexin, C.; Wenxing, L.; Kaiji, Z. Transition metal substituted tungstophosphoric compound catalyzed oxidation of hexanol to hexanal with hydrogen peroxide. React. Kinet. Catal. Lett. 2005, 8, 57-64. [CrossRef]

21. Chen, J.; Liu, J.; Zhang, Y.; Gao, S. Transition metal substituted polyoxometalates and their application in the direct hydroxylation of benzene to phenol with hydrogen peroxide. Res. Chem. Intermed. 2010, 36, 959-968. [CrossRef]

22. Bamoharram, F.F.; Heravi, M.M.; Roshani, M.; Heravi, H.M.; Gharib, A.; Jahangir, M. Lactonization of various diols, using transition metal-substituted keggin catalysts $\left[\mathrm{PW}_{11} \mathrm{MO}_{40}\right]^{7-},(\mathrm{M}=\mathrm{Co}(\mathrm{II}), \mathrm{Ni}(\mathrm{II}), \mathrm{Cu}(\mathrm{II}), \mathrm{Zn}(\mathrm{II})$. Iran. J. Org. Chem. 2009, 1, 110-117.

23. Karcz, R.; Pamin, K.; Połtowicz, J.; Haber, J. Selective Oxidation of Phenol in the Presence of Transition-Metal Substituted Polyoxometalates. Catal. Lett. 2009, 132, 159-167. [CrossRef]

24. Ellis, S.; Kozhevnikov, I.V. Homogeneous oxidation of methyl isobutyrate with oxygen catalysed by metal complexes: Polyoxometalates versus metalloporphyrins and metallophthalocyanines. J. Mol. Catal. A Chem. 2002, 187, 227-235. [CrossRef]

25. Neumann, R.; Dahan, M. Transition metal substituted Keggin type polyoxomolybdates as bifunctional catalysts for the epoxidation of alkenes by molecular oxygen. J. Chem. Soc. Chem. Commun. 1995, 2, 171-172. [CrossRef]

26. Neumann, R.; Levin, M. Molecular Oxygen as Oxidant in Heteropolyanion Catalysed Oxidations. Stud. Surf. Sci. Catal. 1991, 66, 121-127. [CrossRef]

27. Qin, D.; Wang, G.; Wu, Y. Selective oxidation of cyclohexene with molecular oxygen catalyzed by transition metal substituted polyoxometalates. Stud. Surf. Sci. Catal. 1994, 82, 603-608. [CrossRef]

28. Liu, Y.; Murata, K.; Inaba, M. Liquid-phase oxidation of benzene to phenol by molecular oxygen over transition metal substituted polyoxometalate compounds. Catal. Commun. 2005, 6, 679-683. [CrossRef]

29. Kholdeeva, O.A.; Vanina, M.P.; Timofeeva, M.N.; Maksimovskaya, R.I.; Trubitsina, T.A.; Melgunov, M.S.; Burgina, E.B.; Mrowiec-Bialon, J.; Jarzebski, A.B.; Hill, C.L. Co-containing polyoxometalate-based heterogeneous catalysts for the selective aerobic oxidation of aldehydes under ambient conditions. J. Catal. 2004, 226, 363-371. [CrossRef]

30. Maksimchuk, N.V.; Melgunov, M.S.; Chesalov, Y.A.; Mrowiec-Białoń, J.; Jarzębski, A.B.; Kholdeeva, O.A. Aerobic oxidations of $\alpha$-pinene over cobalt-substituted polyoxometalate supported on amino-modified mesoporous silicates. J. Catal. 2007, 246, 241-248. [CrossRef]

31. Mizuno, N.; Hirose, T.; Iwamoto, M. Highly selective epoxidation of olefins on mono-transition-metalsubstituted Keggin-type heteropolytungstates by molecular oxygen in the presence of aldehyde. Stud. Surf. Sci. Catal. 1994, 82, 593-601. [CrossRef]

32. Mizuno, N.; Werner, H.; Finke, R.G. Co-oxidative epoxidation of cyclohexene with molecular oxygen, isobutyraldehyde reductant, and the polyoxoanion-supported catalyst precursor $\left[\left(n-\mathrm{C}_{4} \mathrm{H}_{9}\right)_{4} \mathrm{~N}_{5} \mathrm{Na}_{3}\left[(1,5-\mathrm{COD}) \mathrm{Ir} \cdot \mathrm{P}_{2} \mathrm{~W}_{15} \mathrm{Nb}_{3} \mathrm{O}_{62}\right]\right.$. The importance of key control experiments including omitting the catalyst and adding radical-chain initiators. J. Mol. Catal. 1996, 114, 15-28. [CrossRef]

33. Mizuno, N.; Misono, M. Heteropolyacid catalysts. Curr. Opin. Solid State Mater. Sci. 1997, 2, 84-89. [CrossRef]

34. Kholdeeva, O.A.; Grigoriev, V.A.; Maksimov, G.M.; Fedotov, M.A.; Golovin, A.V.; Zamaraev, K.I. Polyfunctional action of transition metal substituted heteropolytungstates in alkene epoxidation by molecular oxygen in the presence of aldehyde. J. Mol. Catal. A Chem. 1996, 114, 123-130. [CrossRef]

35. Mansuy, D.; Bartoli, J.F.; Battioni, P.; Lyon, D.K.; Finke, R.G. Highly oxidation resistant inorganic-porphyrin analog polyoxometalate oxidation catalysts. 2. Catalysis of olefin epoxidation and aliphatic and aromatic hydroxylations starting from alpha.2- $\mathrm{P}_{2} \mathrm{~W}_{17} \mathrm{O}_{61}(\mathrm{Mn}+$.cntdot. $\mathrm{Br})(\mathrm{n}-11)\left(\mathrm{Mn}^{+}=\mathrm{Mn}^{3+}, \mathrm{Fe}^{3+}, \mathrm{Co}^{2+}, \mathrm{Ni}^{2+}, \mathrm{Cu}^{2+}\right)$, including quantitative comparisons to metalloporphyrin catalysts. J. Am. Chem. Soc. 1991, 113, 7222-7226. [CrossRef]

36. Hill, C.L.; Brown, R.B., Jr. Sustained epoxidation of olefins by oxygen donors catalyzed by transition metal-substituted polyoxometalates, oxidatively resistant inorganic analogs of metalloporphyrins. J. Am. Chem. Soc. 1986, 108, 536-538. [CrossRef]

37. Faraj, M.; Hill, L.C. Sustained catalytic homogenous oxo-transfer oxidation of alkanes. Interaction of alkyl hydroperoxides with transition metal-substituted polyoxometalates. J. Chem. Soc. Chem. Commun. 1987, 19, 1487-1489. [CrossRef] 
38. Matsumoto, Y.; Asami, M.; Hashimoto, M.; Misono, M. Alkane oxidation with mixed addenda heteropoly catalysts containing Ru(III) and Rh(III). J. Mol. Catal. A Chem. 1996, 114, 161-168. [CrossRef]

39. Li, B.; Ma, W.; Han, C.; Liu, J.; Pang, X.; Gao, X. Preparation of MCM-41 incorporated with transition metal substituted polyoxometalate and its catalytic performance in esterification. Microporous Mesoporous Mater. 2012, 156, 73-79. [CrossRef]

40. Maksimchuk, N.V.; Timofeeva, M.N.; Melgunov, M.S.; Shmakov, A.N.; Chesalov, Y.A.; Dybtsev, D.N.; Fedin, V.P.; Kholdeeva, O.A. Heterogeneous Selective Oxidation Catalysts Based on Coordination Polymer MIL-101 and Transition Metal-Substituted Polyoxometalates. J. Catal. 2008, 257, 315-323. [CrossRef]

41. Pamin, K.; Jachimska, B.; Onik, K.; Połtowicz, J.; Grabowski, R. Electrostatic Self-assembly of Polyoxometalates on Chitosan as Catalysts of Oxidation of Cyclic Hydrocarbons. Catal. Lett. 2009, 127, 167-174. [CrossRef]

42. Karcz, R.; Niemiec, P.; Pamin, K.; Połtowicz, J.; Kryściak-Czerwenka, J.; Napruszewska, B.D.; Michalik-Zym, A.; Witko, M.; Tokarz-Sobieraj, R.; Serwicka, E.M. Effect of Cobalt Location in Keggin-Type Heteropoly Catalysts on Aerobic Oxidation of Cyclooctane: Experimental and Theoretical Study. Appl. Catal. A Gen. 2017, 542, 317-326. [CrossRef]

43. Chen, F.; Li, X.; Wang, B.; Xu, T.; Chen, S.L.; Liu, P.; Hu, C. Mechanism of the Cycloaddition of Carbon Dioxide and Epoxides Catalyzed by Cobalt-Substituted 12-Tungstenphosphate. Chem. Eur. J. 2012, 18, 9870-9876. [CrossRef] [PubMed]

44. Yasada, H.; He, L.-N.; Sakakura, T.; Hu, C. Efficient synthesis of cyclic carbonate from carbon dioxide catalyzed by polyoxometalate: The remarkable effects of metal substitution. J. Catal. 2005, 233, 119-122. [CrossRef]

45. Szczepankiewicz, S.H.; Ippolito, C.M.; Santora, B.P.; Van de Ven, T.J.; Ippolito, G.A.; Fronckowiak, L.; Wiatrowski, F.; Power, T.; Kozik, M. Interaction of Carbon Dioxide with Transition-Metal-Substituted Heteropolyanions in Nonpolar Solvents. Spectroscopic Evidence for Complex Formation. Inorg. Chem. 1998, 37, 4344-4352. [CrossRef] [PubMed]

46. Zhang, F.Q.; Zhang, X.M.; Wu, H.S.; Jiao, H. Structural and Electronic Properties of Hetero-Transition-Metal Keggin Anions: A DFT Study of $\alpha / \beta-\left[\mathrm{XW}_{12} \mathrm{O}_{40}\right]^{\mathrm{n}-}\left(\mathrm{X}=\mathrm{Cr}^{\mathrm{VI}}, \mathrm{V}^{\mathrm{V}}, \mathrm{Ti}^{\mathrm{IV}}, \mathrm{Fe}^{\mathrm{III}}, \mathrm{Co}^{\mathrm{III}}, \mathrm{Ni}^{\mathrm{III}}, \mathrm{Co}^{\mathrm{II}}\right.$, and $\left.\mathrm{Zn}^{\mathrm{II}}\right)$ Relative Stability. J. Phys. Chem. A 2007, 111, 159-166. [CrossRef] [PubMed]

47. Maestre, J.M.; Lopez, X.; Bo, C.; Poblet, J.M.; Casan-Pastor, N. Electronic and Magnetic Properties of $\alpha$-Keggin Anions: A DFT Study of $\left[\mathrm{XM}_{12} \mathrm{O}_{40}\right]^{\mathrm{n}-},\left(\mathrm{M}=\mathrm{W}, \mathrm{Mo} ; \mathrm{X}=\mathrm{Al}^{\mathrm{III}}, \mathrm{Si}^{\mathrm{IV}}, \mathrm{P}^{\mathrm{V}}, \mathrm{Fe}^{\mathrm{III}}, \mathrm{Co}{ }^{\mathrm{II}}, \mathrm{Co}{ }^{\mathrm{III}}\right)$ and $\left[\mathrm{SiM}_{11} \mathrm{VO}_{40}\right]^{\mathrm{m}-}$ $(\mathrm{M}=\mathrm{Mo}$ and W). J. Am. Chem. Soc. 2001, 123, 3749-3758. [CrossRef] [PubMed]

48. Glass, E.N.; Fielden, J.; Kaledin, A.L.; Musaev, D.G.; Lian, T.; Hill, C.L. Extending Metal-to-Polyoxometalate Charge Transfer Lifetimes: The Effect of Heterometal Location. Chem. A Eur. J. 2014, 20, 4297-4307. [CrossRef]

49. Fathizadeh, M.; Khivantsev, K.; Pyrzynski, T.J.; Klinghoffer, N.B.; Shakouri, A.N.; Yu, M.; Li, S. Bio-mimetic oxygen separation via a hollow fiber membrane contactor with $\mathrm{O}_{2}$ carrier solutions. Chem. Commun. 2018, 54, 9454-9457. [CrossRef]

50. Pamin, K.; Tabor, E.; Górecka, S.; Kubiak, W.; Rutkowska-Zbik, D.; Połtowicz, J. Three Generations of Cobalt Porphyrins as Catalysts in the Oxidation of Cycloalkanes. ChemSusChem 2019, 12, 684-691. [CrossRef]

51. Mayer, I. Charge, bond order and valence in the AB initio SCF theory. Chem. Phys. Lett. 1983, 97, $270-274$. [CrossRef]

52. Mayer, I. Bond order and valence: Relations to Mulliken's population analysis. Int. J. Quantum Chem. 1984, 26, 151-154. [CrossRef]

53. Nalewajski, R.F.; Mrozek, J.; Michalak, A. Two-electron valence indices from the Kohn-Sham orbitals. Int. J. Quantum Chem. 1997, 61, 589-601. [CrossRef]

54. TURBOMOLE V6.4 2012, a Development of University of Karlsruhe and Forschungszentrum Karlsruhe GmbH, 1989-2007, TURBOMOLE GmbH, Since 2007. Available online: http://www.turbomole.com (accessed on 17 February 2011).

55. Perdew, J.P.; Burke, K.; Ernzerhof, M. Generalized Gradient Approximation Made Simple. Phys. Rev. Lett. 1996, 77, 3865-3868. [CrossRef] [PubMed]

56. Slater, J.C. Quantum Theory of Molecular and Solids; McGraw-Hill: New York, NY, USA, 1974; Volume 4.

57. Perdew, J.P.; Wang, Y. Accurate and simple analytic representation of the electron-gas correlation energy. Phys. Rev. B 1992, 45, 13244-13249. [CrossRef] [PubMed] 
58. Christiansen, P.A.; Ermler, W.C.; Pitze, K.S. Relativistic Effects in Chemical Systems. Ann. Rev. Phys. Chem. 1985, 36, 407-432. [CrossRef]

59. Eichkorn, K.; Treutler, O.; Ohm, H.; Haser, M.; Ahlrichs, R. Auxiliary basis sets to approximate Coulomb potentials. Chem. Phys. Lett. 1995, 240, 283-289. [CrossRef]

60. Eichkorn, K.; Weigend, F.; Treutler, O.; Ahlrichs, R. Auxiliary basis sets for main row atoms and transition metals and their use to approximate Coulomb potentials. Theor. Chem. Acc. 1997, 97, 119-124. [CrossRef]

61. Fletcher, R. Practical Methods of Optimization: Uncostrained Optimization; Band 1; Wiley: New York, NY, USA, 1980.

62. Mitoraj, M.; Michalak, A. Natural orbitals for chemical valence as descriptors of chemical bonding in transition metal complexes. J. Mol. Model. 2007, 13, 347-355. [CrossRef]

63. Michalak, A.; Mitoraj, M.; Ziegler, T. Bond Orbitals from Chemical Valence Theory. J. Phys. Chem. A 2008, 112, 1933-1939. [CrossRef]

64. Mitoraj, M.; Michalak, A.; Ziegler, T. A Combined Charge and Energy Decomposition Scheme for Bond Analysis. J. Chem. Theory Comput. 2009, 5, 962-975. [CrossRef]

(C) 2020 by the authors. Licensee MDPI, Basel, Switzerland. This article is an open access article distributed under the terms and conditions of the Creative Commons Attribution (CC BY) license (http://creativecommons.org/licenses/by/4.0/). 